representative bodies in every nation, asking them each to nominate a delegate to the Congress who would be responsible for promoting its interests in the country which he represents, so as to endeavour to make it a great reunion of all those interested in Ophthalmology throughout the world.

The Executive Committee is composed of the following members :-Mr. E. Treacher Collins, Chairman ; Mr. J. Herbert Fisher, Vice-Chairman ; Mr. Ernest Clarke, Treasurer; Mr. Leslie Paton, 29, Harley Street, London, W., and Mr. R. R. James, 46, Wimpole Street, London, W., Secretaries; Mr. A. B. Cridland; Mr. J. B. Lawford; Mr. Humphrey Neame; Sir John H. Parsons, F.R.S.; Mr. A. H. H. Sinclair.

\title{
The Blind and the Prevention of Blindness
}

In recent years Ministers have recognized, more fully than before, their responsibilities in relation to the blind population of this country and much has been done by parliamentary action in alleviation of the hardships of those to whom sight is denied. In May, 1914, a Departmental Committee was appointed " to consider the condition of the blind and the means available for their industrial or professional training and their assistance, and to make recommendations." Its labours were temporarily suspended on the outbreak of war, but were resumed in March of the following year. The Report of this Committee appeared in 1917 (vide British Journal of Ophthalmology, Vol. II (1918), p. 29).

Reports by Government Committees do not invariably bear fruit, but happily in this instance definite action by the authorities followed the presentation of the Report. One of the earliest results was the appointment by the President of the Local Government Board of an Advisory Committee on the Welfare of the Blind, composed mainly of men and women already engaged in work among the blind and including several who were themselves blind. This Committee was a temporary one and after three years of very valuable work was replaced by a permanent Committee, representative of the registered Societies and Associations for the assistance of blind persons. In 1920 fresh legislation in the interests of the blind was introduced in Parliament and in that year two bills were passed, both of which conferred material benefits on the blind. They are known as the "Blind Persons Act, 1920 " and the "Blind (Education, Employment and Maintenance) Act, 1920." The opening clause of the first of these confers on blind persons the right to the old age pension at the age of fifty. Sighted persons are not eligible for this pension until they attain the age of seventy.

One of the first actions of the original Advisory Committee was the appointment of various sub-Committees, to one of which was referred the important question of the prevention of blindness. It 
soon became evident to the members of this sub-committee that the subject was too large for them to deal with adequately, and in May, 1920, the then Minister of Health (Dr. Addison) appointed another Departmental Committee, under the Chairmanship of the Rt. Hon. G. H. Roberts, M.P., " to investigate and report on the causes of blindness, including defective vision sufficient to impair economic efficiency, and to suggest measures which might be taken for the prevention of blindness." This Committee has recently completed its investigations; its Report* has been published and merits the consideration of all, for there is surely no one to whom measures for the prevention of blindess can fail to appeal. A review of this report will appear in a later issue of this Journal, but as it seems desirable to bring it to the notice of our readers without delay we print the Committee's Conclusions and Recommendations on another page. Meantime we may echo the hope of the members of the Committee that the report will prove as productive of results as its predecessor of 1917 .

\section{Electric Lighting in Ophthalmic Hospitals}

Lighting for ophthalmic work has always been a somewhat difficult problem. For ophthalmoscopic and focal examination of the eye the ideal light is a broad flame which can be readily focussed and easily moved about. In bygone days a candle, paraffin lamp and gas were all used in succession, but all had disadvantages in that they were difficult to move about, or to put quickly and readily into a proper position, and focussing systems of lenses were difficult to adjust in front of them owing to their heat.

When electricity was introduced with the incandescent carbon filament lamp it at once supplanted the other forms of illuminant, as it could be readily moved about and was comparatively free from heat. It also had this advantage, that the globe could be rendered opaque on one side and clear on the other, where it was desired to focus the image of the incandescent filament. The disadvantage of the carbon filament lamps is that their life is short, the globes becoming blackened, the light dull and insufficient. Since the introduction of the metal filament lamp, the manufacture of carbon filament lamps has died out. Unfortunately for ophthalmoscopic purposes metal filament lamps have not up to the present been made sufficiently strong to withstand the strain of constant movement. Where the voltage of current is low it is possible to make metal filament lamps which will stand the amount of jarring that they receive in the course of ordinary ophthalmic work, but where the voltage is high, such as is now the case from practically

\footnotetext{
*Ministry of Health, Departmental Committee on the Causes and Prevention of Blindness. Final Report. To be obtained from H.M. Stationery Office, or through any Bookseller. Price $4 /$.
} 